\title{
Characteristics of emergency department admissions with congestive heart failure in the United States: a Nationwide cross- sectional study
}

Xingyu Zhang ${ }^{1,2^{*}}$ (D) Peilin Qiu ${ }^{3}$, Anna Prushinskaya ${ }^{1}$, Yun Jiang ${ }^{1}$, Hui Fan ${ }^{4^{*}}$ and Sheng Yang ${ }^{5^{*}}$

\begin{abstract}
Background: To understand the characteristics and clinical presentation of patients with Congestive Heart Failure (CHF) visiting the emergency department (ED), and to examine the factors associated with clinical outcomes and medical resource utilization amongst the studied population.

Methods: We analyzed the 2014-2016 ED visit data collected by the National Hospital Ambulatory Medical Care Survey Emergency Department Subfile. We described patients' characteristics and clinical outcomes after ED visits with CHF vs. without CHF. Logistic regression models were used to estimate the association between these characteristics and CHF.

Results: ED visits with CHF visits represented $3.9 \%$ of annual ED visits $(3,647,113$ out of $92,899,685)$. ED patients with CHF were mostly non-Hispanic White (69.9\%). Compared with other ED patients, those with CHF were older, including $71.2 \%$ that were were older than 60 . ED patients with CHF were more likely to be admitted to the hospital (aOR: 2.56; 95\% Cl: 2.28-2.87) and intensive care unit (ICU) (aOR: 2.19; 95\% Cl: 1.77-2.71).

Conclusions: This study describes the demographic, socioeconic, and clinical characteristics of patients who present to the ED with CHF through analysis of a comprehensive national survey. These patients require a higher level of emergency care due to their higher chance of admittance to the hospital and ICU.
\end{abstract}

Keywords: Congestive heart failure, Emergency medicine, National survey, Resource utilization

\footnotetext{
*Correspondence: zhangx28@upmc.edu; 1577371399@qq.com; yangsheng@njmu.edu.cn

'Department of Systems, Populations, and Leadership, University of Michigan School of Nursing, Ann Arbor, MI, USA

${ }^{4}$ Department of Preventive Medicine, North Sichuan Medical College, Nanchong, China

${ }^{5}$ Department of Biostatistics, School of Public Health, Nanjing Medical University, Nanjing, China

Full list of author information is available at the end of the article
}

(C) The Author(s). 2022 Open Access This article is licensed under a Creative Commons Attribution 4.0 International License, which permits use, sharing, adaptation, distribution and reproduction in any medium or format, as long as you give appropriate credit to the original author(s) and the source, provide a link to the Creative Commons licence, and indicate if changes were made. The images or other third party material in this article are included in the article's Creative Commons. licence, unless indicated otherwise in a credit line to the material. If material is not included in the article's Creative Commons licence and your intended use is not permitted by statutory regulation or exceeds the permitted use, you will need to obtain permission directly from the copyright holder. To view a copy of this licence, visit http://creativecommons.org/licenses/by/4.0/ The Creative Commons Public Domain Dedication waiver (http://creativecommons.org/publicdomain/zero/1.0/) applies to the data made available in this article, unless otherwise stated in a credit line to the data. 


\section{Background}

Congestive heart failure (CHF) is a national public health problem in the United States with significant prevalence and mortality $[1,2]$. An estimated 5.7 million people in the United States have CHF [3], and CHF is one of the most common reasons for hospitalization among those 65 and older [4]. With an in increase in the aging population, the substantial healthcare utilization and cost burden of CHF is also growing [5, 6]. Estimated total health care expenditure attributable to heart failure, excluding cost related to comorbidities, is expected to be $\$ 160$ billion [7].

While CHF is a complex clinical syndrome with a variety of etiologies and clinical presentations, many patients with $\mathrm{CHF}$ present with reduced left ventricular function and have the related symptoms of dyspnea with peripheral and pulmonary edema [8]. The absolute fiveyear mortality rate for $\mathrm{CHF}$ is estimated to be $50 \%$, and epidemiological differences in incidence and mortality rates fall along age, racial, and gender lines [8]. For example, Black men represent the highest incidence of CHF, while White women represent the lowest. The highest prevalence of CHF is in those older than 65 [8]. Factors that influence prognosis include medication adherence; CHF patient medication adherence ranges from 7 to $90 \%$, and medication nonadherence is thought to be a leading cause for CHF exacerbation [9]. Another factor associated with increased mortality is anemia, a common finding in patients with $\mathrm{CHF}$ that increases in incidence with worsening $\mathrm{CHF}$ [10]. Additionally, CHF patients who experience infection also experience increased mortality [11]. Finally, within the current context of the COVID-19 pandemic, CHF increases the risk of poor outcomes including intensive care mortality [11].

Visiting the Emergency Department (ED) can often be unavoidable for most patients with CHF. The ED is an important venue for care of patients with CHF $[12,13]$. It was reported that the ED visits numbers for heart failure remained stable, from 914,739 in 2002 to 848,634 in 2010 (annual change $-0.7,95 \%$ CI -3.7 to $+2.5 \%$ ) [14] . Limited previous studies have described characteristics of patients with CHF in the ED. In their secondary analysis of U.S [15]. ED visits for decompensated heart failure, Hugli et al. (2005) found that the average patient was 74 years old and that patients who were white were more likely to be hospitalized. Panduranga et al. (2016) described demographic and clinical characteristics of patients presenting with acute heart failure in Oman and concluded that the mean age was $63 \pm 12$, over half of the patients were male, and that the primary comorbidities were hypertension, coronary artery disease, and diabetes mellitus. Collins et al. (2016) described characteristics of patients with decompensated heart failure who were initially misdiagnosed as patients with non- decompensated heart failure and concluded that these patients were more likely to have a history of COPD and a lower b-type natriuretic peptide (BNP) level [16]. Further understanding the characteristics and clinical presentation of patients with CHF that visit the ED is an initial step towards improving their care and clinical outcomes [17-19]. A comprehensive understanding of ED utilization by patients with CHF may inform ways of reducing this population's ED burden and ways of more effectively addressing these patients' needs.

We performed a secondary data analysis on the $\mathrm{Na}$ tional Hospital Ambulatory Medical Care Survey Emergency Department Subfile (NHAMCS-ED) to estimate the national characteristics of patients with congestive heart failure who utilize the ED, explore the association between congestive heart failure and related clinical presentations, and to follow health outcomes of patients with in the ED setting.

\section{Methods}

The study design and statistical analysis is similar to our previous study on ED visits by patients with depression [20]. We performed a cross-sectional study of the 20142016 ED visit patient data collected by the National Hospital Ambulatory Medical Care Survey Emergency Department Subfile. The study included all adult patients records (age $>18 ; N=42,832$, Weighted $N=$ $278,699,057)[21]$, a nationally representative, multistage, stratified probability sample of ED visits in the United States [22]. The survey design approach and database were introduced in the survey introduction documents $[21,22]$. Generally, the NHAMCS-ED data is a yearly national survey of close to 300 hospital-based EDs from approximately 1900 geographic areas in all 50 states. A standardized data collection form was used to collect detailed information from around 100 patients per hospital-based ED. In total, the NHAMCS-ED included around 20,000-30,000 patients each year.

The primary study outcome is patient congestive heart failure status identified using the variable "congestive heart failure status," which was checked from the patients' electronic health records or claims data. NHAM CS defined congestive heart failure status as including "the inability of the heart to supply sufficient blood flow to meet the needs of the body. Does not include asystole or cardiac arrest."

Secondary outcomes of the study included the Emergency Severity Index (ESI) (a five-level ED triage algorithm assigning patients a score from 1 [most urgent] to 5 [least urgent] on the basis of acuity and resource needs); hospital/intensive care unit (ICU) admission; blood test; medical imaging (including X-ray, CT, ultrasound, and MRI); clinical procedures (BiPAP/CPAP; bladder catheter; cast, splint, wrap; central line other; IV 
fluids; CPR; endotracheal intubation; incision \& drainage; IV fluids; lumbar puncture; nebulizer therapy; pelvic exam; skin adhesives; suturing/staples; other); whether the patient left before triage or treatment; length of stay; and whether the patient died in the ED/hospital.

The study covariates that are examined include demographic characteristics (age, sex, race/ethnicity, region); socioeconomic status indicators, including residence (private home, nursing home, homeless, other) and insurance (private insurance, Medicare, Medicaid/CHIP, uninsured, other); day and mode of arrival; triage vital signs (temperature, pain scale, blood pressure, etc.); and reason for the ED visit.

\section{Statistical analysis}

Population characteristics between congestive heart failure and non-congestive heart failure groups were described and compared. The proportion of medical imaging use among different racial/ethnic groups and covariates between groups were compared using chisquare tests. We used unweighted logistic regression to test the association between the outcome (ED patients with congestive heart failure) and the covariates. We imputed the missing with the median of each covariate when modelling the multivariable logistic regression. $\alpha=0.05$ was set as the statistical significance threshold. We used SAS (version 9.4) for analyses.

\section{Results}

A total of 278,699,057 adult ED visits in the US were reported in the data, corresponding to approximately 92,899,685 annual ED visits from 2014 to 2016 (Table 1). Patients with CHF made up approximately $3.9 \%$ of these visits (equivalent to $10,941,339$ or $3,647,113$ annually). Basic characteristics are described in Table 1. Table 1 shows a comparison of demographic characteristics and disposition status of CHF-related and non-CHF-related visits. The mean age of the population is $47.2( \pm 19.6)$ $(69.5 \pm 15.6$ for CHF and 46.2 \pm 19.2 Non-CHF, $p<$ 0.001 ). The proportion of the male patients is $43.0 \%$ (50.2\% for CHF and $42.7 \%$ Non-CHF, $p<0.001$ ).

The proportion of ED visits by patients with CHF varied by US census region: Northeast, 14.5\%; Midwest, 30.0\%; South, 41.3\%; and West, $14.2 \%(p<0.01)$. A greater proportion of ED patients with $\mathrm{CHF}$ belonged to the $50-59,60-74$, and $>=75$ age groups when compared to their non-CHF counterparts (18.7 vs. $15.2 \%, 28.5$ vs. $15.1 \%$, and 42.7 vs. $10.0 \%$, respectively, $p<0.001$ ). ED patients with CHF comprised a higher proportion of nonHispanic Whites relative to those without CHF (69.9 vs. $62.8 \%, p<0.001)$.

Table 2 describes the selected reasons for visit and emergency diagnosis among ED patients with CHF. Compared with their non-CHF counterparts, patients with $\mathrm{CHF}$ have a greater proportion of visits to the ED for general symptoms, symptoms referable to the cardiovascular and lymphatic system, and symptoms referable to the respiratory system ( $26.6 \%$ vs. $19.0,3.4 \%$ vs. 2.1 , $25.2 \%$ vs. $9.4 \%$, respectively).

Supplemental Table 1 describes associations between the patients' characteristics and their CHF status. Compare to female ED patients, males were 1.35 times more likely to have CHF (aOR: 95\% CI: 1.22-1.50). Among ED patients, Black patients were 1.27 times more likely than White patients to have CHF (aOR: 95\% CI: 1.111.46), while Asian patients were $58 \%$ less likely than White patients to have CHF (aOR: 0.42; 95\% CI: $0.23-$ 0.77). Compared to ED patients inhabiting a private residence, those who were from nursing homes were 1.24 times more likely to have CHF (aOR: 1.24; 95\% CI: 1.01-1.52). Compared to ED patients with private insurance, those with Medicare and Medicaid or CHIP were 2.62 (95\% CI: 2.19-3.13) and 1.90 times (95\% CI: $1.54-$ 2.34), respectively, more likely to have CHF. Patients who arrived by ambulance were 1.86 times more likely to have CHF (95\% CI: 1.66-2.09). Additionally, ED patients who presented with adverse effects of medical/surgical treatment were 1.62 more likely to have CHF than those presenting with injury or trauma (aOR: 1.62; 95\% CI: $1.20-2.19$ ).

Tables 3 and 4 describe the proportions of patients by ESI, hospital admission, ICU admission, and medical resources utilization. The hospital admission rate among ED patients was 2.56 times higher for patients with $\mathrm{CHF}$ (95\% CI: 2.28-2.87); patients have CHF were also 3.03 times more likely to receive immediate vs. semi- or nonurgent ESI scores compared to patients without CHF (95\% CI: 2.48-3.71). The intensive care unit admission rate was 2.19 times higher in patients with CHF $(95 \%$ CI: 1.77-2.71). ED patients with CHF were 2.54 times more likely to receive blood tests (95\% CI: 2.21-2.91), and were more likely to utilize other medical resources; for example, they were 1.69 times more likely to get an ultrasound scan compared to patients without CHF (95\% CI: $1.33-2.15$ ), and were 1.18 times more likely to receive an ultrasound scan compared to patients without procedure (95\% CI: 1.06-1.30).

\section{Discussion}

We presented a comprehensive study on the national characteristics of ED patients with CHF history [14, 23]. Past studies were focused on regionally or only included the ED samples of patients with CHF [14, 23-25]. The current study described the ED patients with CHF with greater power by analyzing a larger, more representative sample. Emergency department is an important component of the CHF healthcare delivery system. Better understanding of the clinical characteristics and health 
Table 1 Baseline characteristics of patients presenting to the ED, stratified by congestive heart failure, NHAMCS 2014-2016

\begin{tabular}{|c|c|c|c|c|c|c|}
\hline & Unweighted & ample, N (\%) & & Weighted Sample & N (\%) & \\
\hline & All & $\begin{array}{l}\text { No Congestive } \\
\text { heart failure }\end{array}$ & $\begin{array}{l}\text { Congestive } \\
\text { heart failure }\end{array}$ & All & $\begin{array}{l}\text { No Congestive } \\
\text { heart failure }\end{array}$ & $\begin{array}{l}\text { Congestive } \\
\text { heart failure }\end{array}$ \\
\hline & 42,832 & $41,106(96.0)$ & $1726(4.0)$ & $278,699,056$ & $267,757,717$ (96.1) & $10,941,339(3.9)$ \\
\hline Male & $18,469(43.1)$ & $17,618(42.9)$ & $851(49.3)$ & $119,751,766(43.0)$ & $114,262,696(42.7)$ & $5,489,071(50.2)$ \\
\hline Age, y & & & & & & \\
\hline $18-39$ & $17,912(41.8)$ & $17,835(43.4)$ & $77(4.5)$ & $118,068,691$ (42.4) & $117,591,074$ (43.9) & $477,617(4.4)$ \\
\hline $40-49$ & $6662(15.6)$ & $6559(16.0)$ & $103(6.0)$ & $43,185,040(15.5)$ & $42,561,872(15.9)$ & $623,169(5.7)$ \\
\hline $50-59$ & $6707(15.7)$ & $6406(15.6)$ & $301(17.4)$ & $42,679,091(15.3)$ & $40,629,523(15.2)$ & $2,049,568(18.7)$ \\
\hline $60-74$ & $6678(15.6)$ & $6165(15.0)$ & $513(29.7)$ & $43,420,164(15.6)$ & 40,300,696 (15.1) & $3,119,467(28.5)$ \\
\hline$>=75$ & $4873(11.4)$ & $4141(10.1)$ & $732(42.4)$ & $31,346,071(11.2)$ & $26,674,553(10.0)$ & $4,671,518(42.7)$ \\
\hline Race/ethnicity & & & & & & \\
\hline White & $27,251(63.6)$ & $26,014(63.3)$ & $1237(71.7)$ & $175,775,546(63.1)$ & $168,129,691(62.8)$ & $7,645,855(69.9)$ \\
\hline Black & $9207(21.5)$ & 8857 (21.5) & $350(20.3)$ & $62,663,628(22.5)$ & $60,262,819(22.5)$ & $2,400,808(21.9)$ \\
\hline Hispanic & $5152(12.0)$ & $5038(12.3)$ & $114(6.6)$ & $33,391,671(12.0)$ & $32,679,875(12.2)$ & $711,796(6.5)$ \\
\hline Asian & $804(1.9)$ & $793(1.9)$ & $11(0.6)$ & 4,392,213 (1.6) & $4,299,639(1.6)$ & $92,574(0.8)$ \\
\hline Other & $418(1.0)$ & $404(1.0)$ & $14(0.8)$ & 2,475,999 (0.9) & 2,385,693 (0.9) & $90,306(0.8)$ \\
\hline Residence type & & & & & & \\
\hline Private residence & $39,819(95.1)$ & $38,335(95.3)$ & $1484(88.3)$ & $258,354,513(95.3)$ & $248,844,348$ (95.5) & $9,510,164(89.1)$ \\
\hline Nursing home & $885(2.1)$ & $725(1.8)$ & $160(9.5)$ & $5,875,161(2.2)$ & $4,935,676(1.9)$ & $939,486(8.8)$ \\
\hline Homeless & $534(1.3)$ & $524(1.3)$ & $10(0.6)$ & $2,480,109(0.9)$ & $2,449,251(0.9)$ & $30,858(0.3)$ \\
\hline Other & $651(1.6)$ & $624(1.6)$ & $27(1.6)$ & $4,501,686(1.7)$ & 4,309,055 (1.7) & $192,631(1.8)$ \\
\hline Insurance type & & & & & & \\
\hline Private insurance & $12,446(30.8)$ & $12,274(31.7)$ & $172(10.3)$ & $79,443,111(30.5)$ & $78,392,584(31.4)$ & $1,050,526(10.0)$ \\
\hline Medicare & $10,517(26.0)$ & $9331(24.1)$ & $1186(71.1)$ & $66,956,323(25.7)$ & $59,480,378(23.8)$ & $7,475,945(71.0)$ \\
\hline Medicaid or CHIP & $11,148(27.6)$ & $10,914(28.2)$ & $234(14.0)$ & $71,529,605(27.5)$ & $69,979,439(28.0)$ & $1,550,166(14.7)$ \\
\hline Uninsured & $4886(12.1)$ & $4833(12.5)$ & $53(3.2)$ & $33,248,283(12.8)$ & $32,969,016(13.2)$ & $279,267(2.7)$ \\
\hline Other & 1406 (3.5) & $1382(3.6)$ & $24(1.4)$ & $9,371,908$ (3.6) & $9,204,758(3.7)$ & $167,149(1.6)$ \\
\hline Year & & & & & & \\
\hline 2014 & $15,319(35.8)$ & $14,710(35.8)$ & $609(35.3)$ & $90,554,699(32.5)$ & $87,207,276(32.6)$ & $3,347,423(30.6)$ \\
\hline 2015 & $14,041(32.8)$ & $13,456(32.7)$ & 585 (33.9) & $89,005,064(31.9)$ & $85,124,272(31.8)$ & $3,880,792(35.5)$ \\
\hline 2016 & $13,472(31.5)$ & $12,940(31.5)$ & $532(30.8)$ & $99,139,294(35.6)$ & $95,426,169(35.6)$ & $3,713,125(33.9)$ \\
\hline Day of Week & & & & & & \\
\hline Sunday & $5622(13.1)$ & $5423(13.2)$ & 199 (11.5) & $35,918,011(12.9)$ & $34,596,685$ (12.9) & $1,321,326(12.1)$ \\
\hline Monday & $6930(16.2)$ & $6641(16.2)$ & $289(16.7)$ & $44,958,717(16.1)$ & $43,076,353(16.1)$ & $1,882,364(17.2)$ \\
\hline Tuesday & $6347(14.8)$ & $6083(14.8)$ & $264(15.3)$ & $40,922,676(14.7)$ & $39,201,202(14.6)$ & $1,721,474(15.7)$ \\
\hline Wednesday & $6225(14.5)$ & $5977(14.5)$ & $248(14.4)$ & $40,888,226(14.7)$ & $39,299,657(14.7)$ & $1588,568(14.5)$ \\
\hline Thursday & $5952(13.9)$ & $5711(13.9)$ & $241(14.0)$ & $39,069,043(14.0)$ & $37,527,610(14.0)$ & $1,541,433(14.1)$ \\
\hline Friday & $5960(13.9)$ & $5693(13.8)$ & $267(15.5)$ & $38,869,467(13.9)$ & $37,170,488(13.9)$ & $1,698,979(15.5)$ \\
\hline Saturday & $5796(13.5)$ & 5578 (13.6) & $218(12.6)$ & $38,072,918(13.7)$ & $36,885,722(13.8)$ & $1,187,196(10.9)$ \\
\hline Arrive by ambulance & 7729 (18.5) & 7023 (17.6) & $706(41.8)$ & $49,769,047(18.3)$ & $45,250,252(17.3)$ & $4,518,795(42.1)$ \\
\hline Seen within last $72 \mathrm{~h}$ & $1914(4.9)$ & $1835(4.9)$ & $79(5.0)$ & $11,953,039(4.8)$ & $11,584,897(4.8)$ & $368,142(3.7)$ \\
\hline Pain level & & & & & & \\
\hline No pain & $7711(24.4)$ & $7216(23.7)$ & $495(41.0)$ & $46,478,004(23.1)$ & $43,617,929(22.6)$ & $2,860,075(37.4)$ \\
\hline Mild & $2916(9.2)$ & 2827 (9.3) & $89(7.4)$ & $18,235,636(9.1)$ & $17,613,003(9.1)$ & $622,633(8.1)$ \\
\hline
\end{tabular}


Table 1 Baseline characteristics of patients presenting to the ED, stratified by congestive heart failure, NHAMCS 2014-2016 (Continued)

\begin{tabular}{|c|c|c|c|c|c|c|}
\hline & \multicolumn{3}{|c|}{ Unweighted Sample, N (\%) } & \multicolumn{3}{|c|}{ Weighted Sample, N (\%) } \\
\hline & All & $\begin{array}{l}\text { No Congestive } \\
\text { heart failure }\end{array}$ & $\begin{array}{l}\text { Congestive } \\
\text { heart failure }\end{array}$ & All & $\begin{array}{l}\text { No Congestive } \\
\text { heart failure }\end{array}$ & $\begin{array}{l}\text { Congestive } \\
\text { heart failure }\end{array}$ \\
\hline Moderate & $9430(29.8)$ & $9146(30.0)$ & $284(23.5)$ & $60,509,861(30.1)$ & $58,733,139(30.4)$ & $1,776,722(23.2)$ \\
\hline Severe & $11,602(36.6)$ & $11,262(37.0)$ & $340(28.1)$ & $75,762,102(37.7)$ & $73,367,325(37.9)$ & $2,394,777(31.3)$ \\
\hline \multicolumn{7}{|l|}{ Temperature } \\
\hline $36^{\circ} \mathrm{C}-38^{\circ} \mathrm{C}$ & $38,083(94.6)$ & $36,621(94.7)$ & $1462(92.2)$ & $249,171,894(95.1)$ & $239,846,217(95.1)$ & $9,325,676(93.2)$ \\
\hline$<=36^{\circ} \mathrm{C}$ & $1522(3.8)$ & $1429(3.7)$ & $93(5.9)$ & $9,089,224(3.5)$ & $8,547,754(3.4)$ & $541,470(5.4)$ \\
\hline$>38^{\circ} \mathrm{C}$ & $635(1.6)$ & $605(1.6)$ & $30(1.9)$ & $3,863,922(1.5)$ & $3,723,158(1.5)$ & $140,763(1.4)$ \\
\hline \multicolumn{7}{|l|}{ Heart Rate, times/min } \\
\hline$<=90$ & $28,489(66.5)$ & $27,286(66.4)$ & $1203(69.7)$ & $184,822,552(66.3)$ & $177,061,313(66.1)$ & $7,761,239(70.9)$ \\
\hline $90-100$ & $7169(16.7)$ & $6930(16.9)$ & $239(13.8)$ & $46,314,663(16.6)$ & $44,873,977(16.8)$ & $1,440,686(13.2)$ \\
\hline $100-110$ & $3906(9.1)$ & $3773(9.2)$ & $133(7.7)$ & $25,427,295(9.1)$ & $24,645,034(9.2)$ & $782,261(7.1)$ \\
\hline $110-120$ & $1988(4.6)$ & $1900(4.6)$ & $88(5.1)$ & $13,118,183(4.7)$ & $12,537,614(4.7)$ & $580,569(5.3)$ \\
\hline$>120$ & $1280(3.0)$ & $1217(3.0)$ & $63(3.7)$ & $9,016,363(3.2)$ & $8,639,779(3.2)$ & $376,583(3.4)$ \\
\hline \multicolumn{7}{|l|}{ DBP mm Hg } \\
\hline $60-80$ & $19,358(45.2)$ & $18,560(45.2)$ & $798(46.2)$ & $125,677,278(45.1)$ & $120,623,428(45.0)$ & $5,053,850(46.2)$ \\
\hline$<60$ & $4312(10.1)$ & 3965 (9.6) & $347(20.1)$ & $26,198,088(9.4)$ & $23,931,635(8.9)$ & $2,266,453(20.7)$ \\
\hline$>80$ & $19,162(44.7)$ & $18,581(45.2)$ & $581(33.7)$ & $126,823,690(45.5)$ & $123,202,654(46.0)$ & $3,621,036(33.1)$ \\
\hline \multicolumn{7}{|l|}{$\mathrm{SBP} \mathrm{mm} \mathrm{Hg}$} \\
\hline $80-120$ & $9773(22.8)$ & $9322(22.7)$ & $451(26.1)$ & $61,351,488(22.0)$ & $58,394,721(21.8)$ & $2,956,767(27.0)$ \\
\hline$<80$ & $1588(3.7)$ & $1513(3.7)$ & $75(4.3)$ & $9,419,022(3.4)$ & $9,005,031(3.4)$ & $413,990(3.8)$ \\
\hline$>120$ & $31,471(73.5)$ & $30,271(73.6)$ & $1200(69.5)$ & $207,928,547$ (74.6) & $200,357,965$ (74.8) & $7,570,582(69.2)$ \\
\hline \multicolumn{7}{|l|}{ Census Region } \\
\hline Northeast & $7176(16.8)$ & $6937(16.9)$ & $239(13.8)$ & 43,967,048 (15.8) & $42,383,250(15.8)$ & $1,583,797(14.5)$ \\
\hline Midwest & $10,893(25.4)$ & $10,343(25.2)$ & $550(31.9)$ & $74,304,118(26.7)$ & $71,017,621(26.5)$ & $3,286,496(30.0)$ \\
\hline South & $15,430(36.0)$ & 14,760 (35.9) & $670(38.8)$ & $105,760,507$ (37.9) & $101,247,049$ (37.8) & $4,513,457(41.3)$ \\
\hline West & $9333(21.8)$ & $9066(22.1)$ & $267(15.5)$ & $54,667,385(19.6)$ & $53,109,796(19.8)$ & $1,557,589(14.2)$ \\
\hline \multicolumn{7}{|l|}{ This visit is related to } \\
\hline Injury/trauma & $12,286(30.1)$ & $12,006(30.7)$ & $280(17.1)$ & $78,178,483(29.5)$ & $76,464,334(30.0)$ & $1,714,149(16.6)$ \\
\hline Overdose/poisoning & $499(1.2)$ & $490(1.3)$ & $9(0.5)$ & $3,358,380(1.3)$ & $3,313,963(1.3)$ & $44,417(0.4)$ \\
\hline $\begin{array}{l}\text { Adverse effect of } \\
\text { medical/surgical treatment }\end{array}$ & $1099(2.7)$ & $1038(2.7)$ & $61(3.7)$ & $7,170,683(2.7)$ & $6,768,702(2.7)$ & $401,982(3.9)$ \\
\hline Visit not related to any above & $26,692(65.4)$ & $25,413(64.9)$ & $1279(78.1)$ & $174,903,611(66.0)$ & $166,770,439(65.4)$ & $8,133,172(78.6)$ \\
\hline Questionable injury status & $214(0.5)$ & $206(0.5)$ & $8(0.5)$ & $1,546,669(0.6)$ & $1,494,095(0.6)$ & $52,574(0.5)$ \\
\hline
\end{tabular}

outcomes of CHF ED patients is a first step to improving the healthcare and treatment of these patients as well as ED encounters in this population.

This study reports new epidemiological characteristics on ED patients with CHF including their demographics, presenting vitals, hospital/ICU admission, and medical imaging / lab test resource utilization. We found demographic differences were associated with the prevalence of CHF in ED patients. For example, EDs in the South region had the largest proportion of visits by patients with CHF. Female ED patients were less likely than males to have $\mathrm{CHF}$, and non-Hispanic White patients were more likely to have $\mathrm{CHF}$ than other races/ethnicities. These differences are generally consistent with the demographic patterns in CHF prevalence in the US. We also found that CHF patients with Medicare and Medicaid or CHIP were more likely to visit the ED than were patients with private insurance. This higher likelihood of ED visitation in CHF patients with Medicare and Medicate or CHIP could be related to increased medication nonadherence in $\mathrm{CHF}$ patients with Medicare and Medicaid [26]. CHF patients who visited the ED were also 
Table 2 Selected Reason for Visit and Emergency Department Diagnosis among ED Patients with Congestive heart failure, NHAMCS 2014-2016

\begin{tabular}{|c|c|c|c|c|c|c|}
\hline & \multicolumn{3}{|c|}{ Unweighted Sample } & \multicolumn{3}{|l|}{ Weighted Sample } \\
\hline & All & $\begin{array}{l}\text { No Congestive } \\
\text { heart failure }\end{array}$ & $\begin{array}{l}\text { Congestive } \\
\text { heart failure }\end{array}$ & All & $\begin{array}{l}\text { No Congestive } \\
\text { heart failure }\end{array}$ & $\begin{array}{l}\text { Congestive } \\
\text { heart failure }\end{array}$ \\
\hline \multicolumn{7}{|l|}{ Reason for visit } \\
\hline General Symptoms & 8187 (19.1) & 7734 (18.8) & $453(26.3)$ & $53,664,580(19.3)$ & $50,769,980(19.0)$ & $2,894,600(26.6)$ \\
\hline $\begin{array}{l}\text { Symptoms Referable to } \\
\text { Psychological and } \\
\text { Mental Disorders }\end{array}$ & $1700(4.0)$ & $1646(4.0)$ & $54(3.1)$ & $9,426,523(3.4)$ & $9,138,510(3.4)$ & $288,013(2.6)$ \\
\hline $\begin{array}{l}\text { Symptoms Referable to } \\
\text { the Nervous System }\end{array}$ & $3304(7.7)$ & $3234(7.9)$ & $70(4.1)$ & $20,833,741(7.5)$ & $20,455,816(7.7)$ & $377,925(3.5)$ \\
\hline $\begin{array}{l}\text { Symptoms Referable to } \\
\text { the Cardiovascular and } \\
\text { Lymphatic Systems }\end{array}$ & $889(2.1)$ & $823(2.0)$ & $66(3.8)$ & $5,993,917(2.2)$ & $5,625,049(2.1)$ & $368,869(3.4)$ \\
\hline $\begin{array}{l}\text { Symptoms Referable to } \\
\text { the Eyes and Ears }\end{array}$ & $848(2.0)$ & $839(2.0)$ & $9(0.5)$ & $5,778,778(2.1)$ & $5,721,193(2.1)$ & $57,585(0.5)$ \\
\hline $\begin{array}{l}\text { Symptoms Referable to } \\
\text { the Respiratory System }\end{array}$ & $4198(9.8)$ & $3721(9.1)$ & $477(27.7)$ & $27,856,021(10.0)$ & $25,110,566$ (9.4) & $2,745,455(25.2)$ \\
\hline $\begin{array}{l}\text { Symptoms Referable to } \\
\text { the Digestive System }\end{array}$ & $6807(15.9)$ & $6629(16.2)$ & $178(10.3)$ & $46,038,272(16.5)$ & $44,684,121(16.7)$ & $1,354,151(12.4)$ \\
\hline $\begin{array}{l}\text { Symptoms Referable to } \\
\text { the Genitourinary System }\end{array}$ & $2477(5.8)$ & $2442(6.0)$ & $35(2.0)$ & $14,984,361(5.4)$ & $14,774,942(5.5)$ & $209,419(1.9)$ \\
\hline $\begin{array}{l}\text { Symptoms Referable to } \\
\text { the Skin, Nails, and Hair }\end{array}$ & $1333(3.1)$ & $1303(3.2)$ & $30(1.7)$ & $8,716,118(3.1)$ & $8,534,035(3.2)$ & $182,083(1.7)$ \\
\hline $\begin{array}{l}\text { Symptoms Referable to } \\
\text { the Musculoskeletal System }\end{array}$ & $6519(15.2)$ & $6356(15.5)$ & $163(9.5)$ & $42,820,579(15.4)$ & $41,594,610(15.6)$ & $1,225,969(11.2)$ \\
\hline Other & $6501(15.2)$ & $6312(15.4)$ & $189(11.0)$ & $42,147,135(15.1)$ & $40,949,503(15.3)$ & $1,197,632(11.0)$ \\
\hline
\end{tabular}

more likely to arrive by ambulance likely because patients with worsening CHF may be more likely to use an ambulance than other types of patients [27]. These findings indicate that increased focus on medication adherence in Medicare and Medicaid patients as well as further attention to management of CHF patients during ambulance transfer may be pertinent areas for further research to improve clinical outcomes.

Patients with CHF had over 3.6 million ED visits each year nationally. Compared to non-CHF ED visits, patients with CHF in the ED present higher ESI scores, higher chance of hospital/ICU admission, as well as undergoing a blood test and ultrasound scan. This indicates that a higher level of emergency care is needed among patients with $\mathrm{CHF}$ require. This increased use of hospital resources is consistent with previous research suggesting greater utilization of hospital resources by CHF patients, including a significant rate of hospital readmission among CHF patients [28]. This indicates that better allocation of ED, and intensive care units with resources for preparedness and better case management of elderly black or non-Hispanic White are needed for patients with $\mathrm{CHF}$.

Exploration of the reasons for ED visits and revisits among CHF patients may contribute to the development of interventions to reduce ED visits and revisit rates among these patients. Emergency department is an understudied setting for CHF healthcare delivery, considering the large number of ED visits among patients with CHF. More detailed patients' history data of CHF are needed for future study, which can help inform approaches of increasing these patients' use of routine care over ED care. The higher rate of hospital and ICU admission indicates that $\mathrm{CHF}$ patients require a higher level of emergency care. These findings suggest that increased recognition of the potential of the ED as a highleverage setting for improving treatment and screening of CHF is needed, which can be developed by identifying characteristics and trajectories of patients presenting to the ED with CHF.

There were several limitations to the present study. First, information regarding to the severity and stage of $\mathrm{CHF}$ was not gathered in NHAMCS-ED dataset. Secondly, the NHAMCS-ED survey data does not contains information on treatment history (e.g. pharmacologic) for CHF. Future studies may examine more data related to CHF characteristics, comorbidities, treatment history, and other finer-grained clinical data, which allows for better understanding of the associated factors related to CHF ED care. Thirdly, the data on the acute and chronic 
Table 3 Proportion of Emergency Severity Index, Hospital admission, ICU admission, Medical resources utilization, stratified by Congestive heart failure, NHAMCS 2014-2016

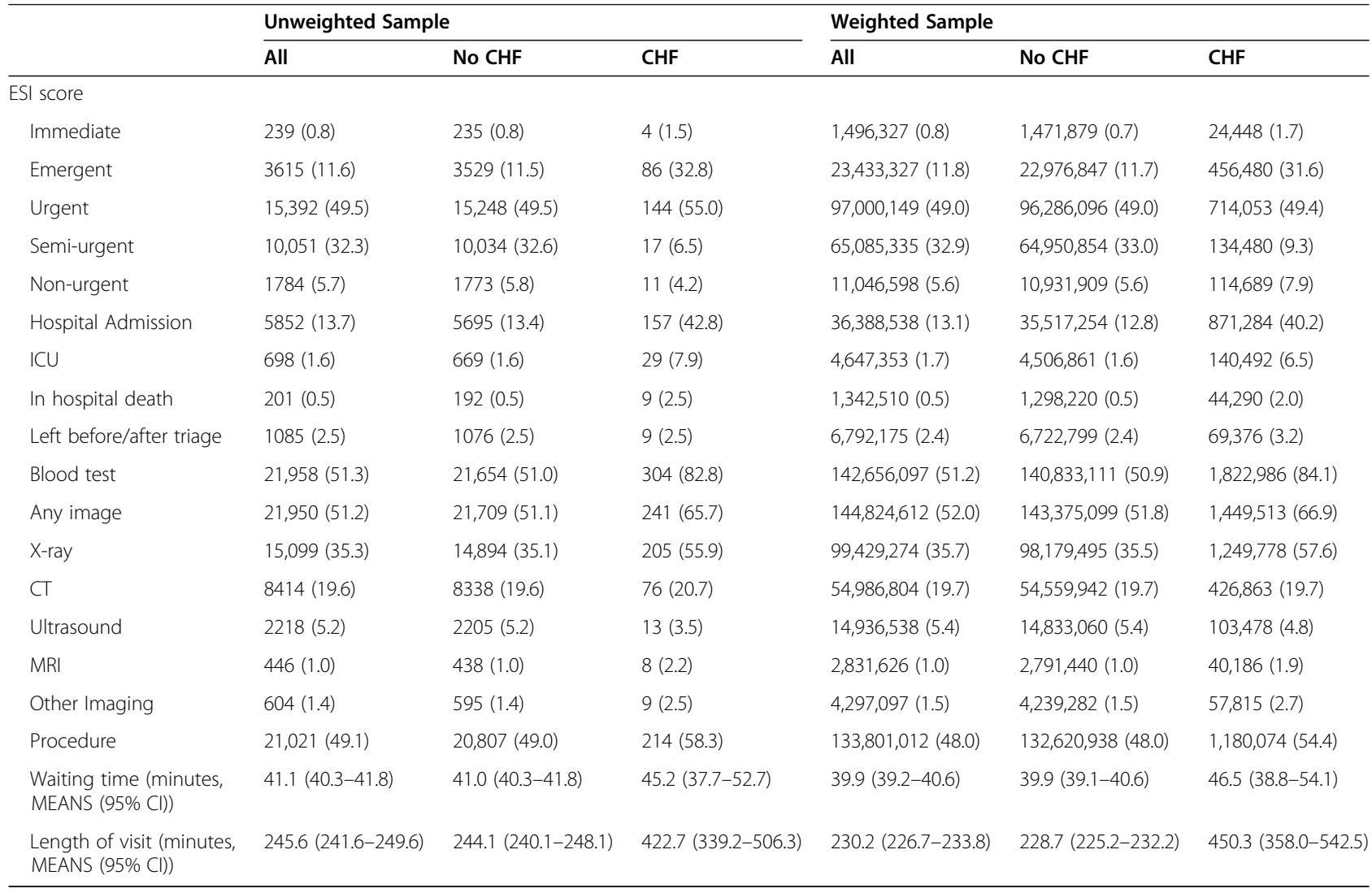

Notes: Waiting time-time from arrival to seeing the physician; Length of visit-time from arrival to discharge

Table 4 Odds Ratio of Emergency Severity Index, Hospital admission, ICU admission, Medical Resources Utilization for Congestive heart failure vs. Non-congestive heart failure Patients, NHAMCS 2014-2016

\begin{tabular}{|c|c|c|c|c|}
\hline & \multirow{2}{*}{$\begin{array}{l}\text { Crude Odds } \\
\text { Ratio }\end{array}$} & \multicolumn{3}{|l|}{ Adjusted for } \\
\hline & & Demographics & + Social economic & + Visiting \& Clinical \\
\hline $\begin{array}{l}\text { ESI Score: Immediate or Emergent vs. } \\
\text { Semi- or Non-Urgent }\end{array}$ & $6.92(5.77-8.30)$ & $3.98(3.30-4.81)$ & $3.87(3.21-4.68)$ & $3.03(2.48-3.71)$ \\
\hline ESI Score: Urgent vs. Semi- or Non-Urgent & $3.24(2.75-3.82)$ & $2.32(1.96-2.75)$ & $2.28(1.93-2.70)$ & $2.07(1.74-2.47)$ \\
\hline Hospital Admission & $5.78(5.24-6.39)$ & $3.14(2.83-3.49)$ & $3.00(2.70-3.33)$ & $2.56(2.28-2.87)$ \\
\hline $\mathrm{ICU}$ & $6.85(5.67-8.28)$ & $3.43(2.82-4.19)$ & $3.17(2.59-3.87)$ & $2.19(1.77-2.71)$ \\
\hline Death & $5.11(3.54-7.38)$ & $1.98(1.36-2.90)$ & $1.87(1.27-2.74)$ & $1.05(0.69-1.62)$ \\
\hline Left before/after triage & $0.46(0.30-0.72)$ & $0.71(0.46-1.11)$ & $0.64(0.41-1.00)$ & $0.60(0.38-0.93)$ \\
\hline Blood test & $4.43(3.92-5.01)$ & $2.93(2.59-3.33)$ & $2.88(2.53-3.27)$ & $2.54(2.21-2.91)$ \\
\hline Any imaging & $2.91(2.61-3.25)$ & $1.86(1.66-2.09)$ & $1.85(1.65-2.07)$ & $1.77(1.57-1.99)$ \\
\hline X-ray & $3.52(3.18-3.89)$ & $2.27(2.04-2.52)$ & $2.21(1.99-2.45)$ & $2.00(1.79-2.24)$ \\
\hline$C T$ & $1.33(1.19-1.49)$ & $0.83(0.74-0.93)$ & $0.82(0.73-0.93)$ & $0.90(0.79-1.02)$ \\
\hline Ultrasound & $0.96(0.77-1.20)$ & $1.43(1.13-1.80)$ & $1.52(1.20-1.92)$ & $1.69(1.33-2.15)$ \\
\hline MRI & $0.83(0.49-1.39)$ & $0.54(0.32-0.91)$ & $0.59(0.35-1.00)$ & $0.76(0.44-1.30)$ \\
\hline Procedure & $1.33(1.21-1.46)$ & $1.19(1.08-1.31)$ & $1.19(1.08-1.32)$ & $1.18(1.06-1.30)$ \\
\hline
\end{tabular}

Note: ${ }^{*}+$ Demographics include: gender, age group, race/ethnicity; +Social economic: residence type, insurance type, census region; + Visiting \& Clinical: year, week of day, arrive by ambulance, seen within last $72 \mathrm{~h}$, pain level, temperature, heart rate, dialytic blood pressure, injury status, reason for visit 
CHF is unknown in the survey, which should be collected in the future studies.

\section{Conclusion}

This study describes the demographic, socioeconomic, and clinical characteristics of patients who present to the ED with CHF through analysis of a comprehensive national survey. The study describes the characteristics of CHF patients who visit the ED on a national scale. We found that there are gender, age, and racial/ethnic differences between ED patients with and without CHF. These patients require a higher level of emergency care due to their higher chance of admittance to the hospital and ICU.

\section{Abbreviations}

aOR: Adjusted odds ratio; Cl: Confidential interval; ED: Emergency department; NHAMCS-ED: National Hospital Ambulatory Medical Care Survey ED Subfile; ESI: Emergency severity index; ICU: Intensive care unit; $\mathrm{CT}$ : Computed tomography; MRI: Magnetic resonance imaging; CHF: Congestive heart failure

\section{Supplementary Information}

The online version contains supplementary material available at https://doi. org/10.1186/s12873-021-00564-7

Additional file 1: Supplement Table 1. Association between ED visiting with Congestive heart failure and patient visiting characteristics, NHAMCS 2014-2016. Note: the adjusted OR was from a logistic regression including all variables in the table.

\section{Acknowledgements}

None.

\section{Authors' contributions}

$X Z$ had full access to all the data in the study and take responsibility for the integrity of the data and the accuracy of the data analysis. Concept and design: XZ, PQ. Acquisition, analysis, or interpretation of data: All authors. Drafting of the manuscript: $P Q, X Z$. Critical revision of the manuscript for important intellectual content: YJ, HF, SY,AP. Statistical analysis: XZ. Obtained funding: $X Z, H F, S Y$. Administrative, technical, or material support: PQ. All authors have read and approved the manuscript. Conflict of Interest Disclosures: None reported.

\section{Funding}

This study was supported by Michigan Institute for Clinical and Health Research (MICHR No. UL1TR002240). This work was also supported by the National Natural ScienceFoundation of China (no. 81703321) and the Priority Academic Program Development of Jiangsu Higher Education Institutions (PAPD). The funders played no role in the design of the study, collection, analysis or interpretation of data, or writing of the manuscript.

\section{Availability of data and materials}

The NHAMCS-ED dataset can be accessed through the website of the US Centers for Disease Control and Prevention (CDC) (https://www.cdc.gov/ nchs/ahcd/index.htm). The detailed explanation of the survey data for each year and the code book can be found here: https://ftp.cdc.gov/pub/Health Statistics/NCHS/dataset_documentation/nhamcs/.

\section{Declarations}

\section{Ethics approval and consent to participate}

This study was a secondary analysis of a public database and did not require ethical approval.
Consent for publication

Not applicable.

\section{Competing interests}

The authors declare that they have no competing interests. The funders/ sponsors had no role in the design and conduct of the study; collection, management, analysis, and interpretation of the data; preparation, review, or approval of the manuscript; and decision to submit the manuscript for publication.

\section{Author details}

${ }^{1}$ Department of Systems, Populations, and Leadership, University of Michigan School of Nursing, Ann Arbor, MI, USA. ${ }^{2}$ Thomas E. Starzl Transplantation Institute, University of Pittsburgh Medical Center, Pittsburgh, PA, USA. ${ }^{3}$ College of Literature, Science, and the Arts, University of Michigan, Ann Arbor, MI, USA. ${ }^{4}$ Department of Preventive Medicine, North Sichuan Medical College, Nanchong, China. ${ }^{5}$ Department of Biostatistics, School of Public Health, Nanjing Medical University, Nanjing, China.

Received: 7 August 2020 Accepted: 24 December 2021

Published online: 28 January 2022

\section{References}

1. Ziaeian B, Fonarow GC. Epidemiology and aetiology of heart failure. Nat Rev Cardiol. 2016;13(6):368-78. https://doi.org/10.1038/nrcardio.2016.25.

2. Savarese G, Lund LH. Global public health burden of heart failure. Card Fail Rev. 2017;3(1):7-11. https://doi.org/10.15420/cfr.2016:25:2.

3. Hoban MB, Fedor M, Reeder S, Chernick M. The effect of telemonitoring at home on quality of life and self-care behaviors of patients with heart failure. Home Healthcare Now. 2013;31(7):368-77. https://doi.org/10.1097/NHH. Ob013e318291fd56.

4. Hall MJ, Levant S, DeFrances CJ. Hospitalization for congestive heart failure: United States, 2000-2010. US Department of Health and Human Services, Centers for Disease Control and Prevention, National Center for Health Statistics; 2012.

5. O'Connell JB. The economic burden of heart failure. Clin Cardiol. 2000; 23(S3):|ll6-III10. https://doi.org/10.1002/clc.4960231503.

6. Cook C, Cole G, Asaria P, Jabbour R, Francis DP. The annual global economic burden of heart failure. Int J Cardiol. 2014;171(3):368-76. https:// doi.org/10.1016/j.ijcard.2013.12.028.

7. Farmakis D, Filippatos G, Parissis J, Lekakis J. The social and economic burden of hospitalization for heart failure. Medicographia. 2015;37(2):135-8.

8. Malik ABD, Chhabra L. Congestive Heart Failure. [Updated 2020 Aug 10]. In: StatPearls [Internet]. Treasure Island (FL): StatPearls Publishing; 2020.

9. Wu J-R, Moser DK, Chung ML, Lennie TA. Predictors of medication adherence using a multidimensional adherence model in patients with heart failure. J Card Fail. 2008;14(7):603-14. https://doi.org/10.1016/j.cardfail.2008.02.011.

10. Wilson S. Evaluation and management of anemia and iron deficiency in adults with heart failure; 2020.

11. Drozd M, Garland E, Walker AMN, Slater TA, Koshy A, Straw S, Gierula J, et al. Infection-Related Hospitalization in Heart Failure With Reduced Ejection Fraction: A Prospective Observational Cohort Study. Circulation: Heart Failure. 2020;13(5):e006746.

12. Martindale JL, Wakai A, Collins SP, Levy PD, Diercks D, Hiestand BC, et al. Diagnosing acute heart failure in the emergency department: a systematic review and meta-analysis. Acad Emerg Med. 2016;23(3):223-42. https://doi. org/10.1111/acem.12878

13. Miró Ò, Levy PD, Möckel M, Pang PS, Lambrinou E, Bueno H, et al. Disposition of emergency department patients diagnosed with acute heart failure: an international emergency medicine perspective. Eur J Emerg Med. 2017;24(1):2-12. https://doi.org/10.1097/MEJ.0000000000000411.

14. Blecker S, Ladapo JA, Doran KM, Goldfeld KS, Katz S. Emergency department visits for heart failure and subsequent hospitalization or observation unit admission. Am Heart J. 2014;168(6):901-8. https://doi.org/10.1016/j.ahj.2014.08.002.

15. Panduranga $P$, Sulaiman $K$, Al-Zakwani I, Alazzawi AA, Abraham A, Singh $P P$, et al. Demographics, clinical characteristics, management, and outcomes of acute heart failure patients: observations from the oman acute heart failure registry. Oman Med J. 2016;31(3):188-95. https://doi. org/10.5001/omj.2016.37.

16. Collins SP, Lindsell CJ, Peacock WF, Eckert DC, Askew J, Storrow AB. Clinical characteristics of emergency department heart failure patients initially 
diagnosed as non-heart failure. BMC Emerg Med. 2006;6(1):11. https://doi. org/10.1186/1471-227X-6-11.

17. Janke AT, McNaughton CD, Brody AM, Welch RD, Levy PD. Trends in the incidence of hypertensive emergencies in US emergency departments from 2006 to 2013. J Am Heart Assoc. 2016;5(12):e004511. https://doi.org/10.11 61/JAHA.116.004511.

18. Ullo M, Sugalski G, Marco CA. Volume Overload: Acute Decompensated Heart Failure in the Emergency Department. Emerg Med Rep. 2019;40(9).

19. Hugli O, Braun JE, Kim S, Pelletier AJ, Camargo CA Jr. United States emergency department visits for acute decompensated heart failure, 1992 to 2001. Am J Cardiol. 2005;96(11):1537-42. https://doi.org/10.1016/j.amjca rd.2005.07.064.

20. Hill T, Jiang Y, Friese CR, Darbes LA, Blazes CK, Zhang X. Analysis of emergency department visits for all reasons by adults with depression in the United States. BMC Emerg Med. 2020;20(1):1-11. https://doi.org/10.11 86/s1 2873-020-00347-6.

21. Hsiao CJ: Understanding and using NAMCS and NHAMCS data. In.; 2016.

22. Cox L. Housing status, patient characteristics, and ED utilization associated with medication prescribing at ED discharge among homeless and nonhomeless adults in urban hospitals in the United States; 2018.

23. Hasegawa K, Tsugawa Y, Camargo CA Jr, Brown DFM. Frequent utilization of the emergency department for acute heart failure syndrome: a populationbased study. Circ Cardiovasc Qual Outcomes. 2014;7(5):735-42. https://doi. org/10.1161/CIRCOUTCOMES.114.000949.

24. Collins SP, Lindsell CJ, Storrow AB, Abraham WT, Committee ASA, Investigators, study G. Prevalence of negative chest radiography results in the emergency department patient with decompensated heart failure. Ann Emerg Med. 2006;47(1):13-8. https://doi.org/10.1016/j.annemergmed.2005. 04.003.

25. Storrow AB, Collins SP, Lyons MS, Wagoner LE, Gibler WB, Lindsell CJ. Emergency department observation of heart failure: preliminary analysis of safety and cost. Congestive Heart Fail. 2005;11(2):68-72. https://doi.org/1 0.1111/j.1527-5299.2005.03844.x.

26. Bagchi AD, Esposito D, Kim M, Verdier J, Bencio D. Utilization of, and adherence to, drug therapy among medicaid beneficiaries with congestive heart failure. Clin Ther. 2007;29(8):1771-83. https://doi.org/10.1016/j. clinthera.2007.08.015.

27. Harjola P, Tolonen J, Boyd J, Mattila J, Koski R, Palomäki A, et al. The role of pre-hospital management in acute heart failure. Eur J Heart Fail. 2017;19(2): 287-9. https://doi.org/10.1002/ejhf.712.

28. Chamberlain RS, Sond J, Mahendraraj K, Lau CSM, Siracuse BL. Determining 30-day readmission risk for heart failure patients: the readmission after heart failure scale. Int J Gen Med. 2018;11:127-41. https://doi.org/10.2147/JJGM.S1 50676.

\section{Publisher's Note}

Springer Nature remains neutral with regard to jurisdictional claims in published maps and institutional affiliations.

Ready to submit your research? Choose BMC and benefit from:

- fast, convenient online submission

- thorough peer review by experienced researchers in your field

- rapid publication on acceptance

- support for research data, including large and complex data types

- gold Open Access which fosters wider collaboration and increased citations

- maximum visibility for your research: over $100 \mathrm{M}$ website views per year

At BMC, research is always in progress.

Learn more biomedcentral.com/submissions 